\title{
Including Value Orientations in Choice Models to Estimate Benefits of Wildlife Management Policies
}

\author{
Gianluca Grilli $^{\mathrm{a}, \mathrm{b}, *}$, Sandra Notaro ${ }^{\mathrm{c}}$, Danny Campbell ${ }^{\mathrm{d}}$ \\ ${ }^{a}$ Economic and Social Research Institute, Sir John Rogerson's Quay, Dublin, Ireland \\ ${ }^{b}$ Trinity College Dublin, Dublin, Ireland \\ ${ }^{c}$ Department of Economics and Management, University of Trento, Italy \\ ${ }^{d}$ Economics Division, University of Stirling, Stirling FK9 4LA, United Kingdom
}

\begin{abstract}
Value orientations towards wildlife affect the way people perceive nature and their connection with animals. In particular, the social psychological literature within the environmental field suggests that there are two main orientations of people towards wildlife: mutualism and domination. This body of literature has shown how wildlife value orientations can serve as predictors of attitudes and behaviours toward wildlife and form the foundation of human-wildlife conflicts. A common approach in the non-market valuation literature is to include information on attitudes and values in the deterministic part of the utility function, leading to problems of endogeneity bias. To avoid this, analysts have recently shifted their attention to approaches based on latent variables. This paper presents an application of a latent variable and latent class model, to understand how latent orientations influence choices, in a case study in the Italian Alps. The intuition is that different underlying individual value orientation affects preferences and the level of willingness to pay and should be therefore considered in choice models. The latent variable is used to explain class membership of respondents. Results indicate that the latent variable has a significant effect in class allocation and that the hybrid model performs better than a simple two class model. Results provide guidance on the social acceptability of management interventions and can support public decision-makers in the modulation of wildlife management policies for balancing the needs of conservation and outdoor recreation, explicitly considering existing human-wildlife conflicts.
\end{abstract}

Keywords: choice experiment, hybrid model, value orientation, endangered species, latent class model 2010 MSC: 00-01, 99-00

Accepted refereed manuscript of: Grilli G, Notaro S \& Campbell D (2018) Including Value Orientations in Choice Models to Estimate Benefits of Wildlife Management Policies, Ecological Economics, 151, pp. 70-81.

DOI: $10.1016 /$ j.ecolecon.2018.04.035

(c) 2018, Elsevier. Licensed under the Creative Commons Attribution-NonCommercial-NoDerivatives 4.0 International http://creativecommons.org/licenses/by-nc-nd/4.0/

\footnotetext{
${ }^{*}$ Corresponding author

Email address: gianluca.grilli@esri.ie (Gianluca Grilli )
} 


\section{Introduction}

Conservation of wildlife is of primary importance worldwide, due to the alarming rate of biodiversity loss affecting many natural areas. The population of several species has sharply decreased, mainly due to hunting and habitat depletion. Economic valuation of biodiversity with stated preference methods, within this framework, may be extremely beneficial to inform policy makers about people's attitudes and preferences towards management alternatives. It is well-recognised in the literature that, when making choices in the environmental field, people are led by several cognitive variables, such as attitudes, values and social norms. In particular, value orientations (VOs) seem to play an important role in the individual choice process. Wildlife VOs are defined as representing broad, cultural ideological believes, that orient and provide personal meaning to basic values related to wildlife (Teel and Manfredo, 2010). In the literature, it is possible to identify two main orientations towards wildlife (Manfredo, 2008): dominance and mutualism. People with a dominant orientation tend to think that wildlife should be managed for the benefits of mankind. On the other hand, a person with a mutualism orientation place humans and animals nearly on the same level; animals are seen as creatures deserving rights and care.

Choice experiments (CE) are typical examples of techniques aiming at studying how people make choices. Value orientations affect choices, which means that they should be therefore taken into account by the analyst in CE surveys. A common approach in the non-market valuation literature is to use information about attitudes and values, which are collected by means of Likert scales, in the deterministic part of the utility function. However, such indicators are likely correlated to other non-observed individual characteristics, thus leading to problems of endogeneity bias (Hess and Stathopoulos, 2013). For the cited reasons, latent variable methods are gaining popularity. Such methods acknowledge that what is observed is only answers to VO questions and not the real orientation. In this vision, a latent variable is included in the model, in order to explain simultaneously the behaviour of the respondent in the stated choice survey and in the value orientation questions. Value orientations are no longer in the deterministic part of the utility function but treated as dependent variables, estimated simultaneously to the choice model, thus eliminating problems connected with endogeneity.

In this paper, we apply the latent variable approach in a CE hybrid estimation for valuing tourists preferences for endangered species management. The main methodological contribution is to include specific value orientations as measures of individual attitudes in the set of structural equations. We expect that value orientations are linked to willingness to pay (WTP) and that they can be used to explain preference heterogeneity for wildlife conservation.Structural equations are modelled as ordered logit, while the choice model with a latent class model. The latent variable is used as explanatory variable for the value orientation and then enters the choice model in the class allocation function. We show how the inclusion of value orientations can improve WTP estimates, with relevant policy implications. The method is applied to a case study about wildlife management in the Italian Alps, the Province of Trento (Trentino). We consider three wildlife species, i.e. wolf, lynx and salamander, and we ask to a sample of local tourists whether they are willing to pay for an increase in their population. Wolves and lynx were naturally abundant in Trentino until the end of the 19th century. Later on, due to hunting and bad habitat conditions, their population decreased rapidly, bringing to their extinction. In recent years, the increased habitat quality provoked a natural return of some specimen from close areas, but their number is not enough to assure reproduction. At the same time, the case of salamander is interesting as well. In fact, a particular sub-species of Salamander, called salamander of Aurora, lives only in a limited area of Trentino and in a valley of a neighbouring region. Establishing a viable population for these species is a primary challenge for local decision-makers, in order to assure a long-lasting conservation, in this context the investigation of tourist preferences might help in designing more effective policies.

\section{Value Orientation Theory}

Human-widlife relationships and interactions derive from the cognitive basis that forms human thought and behaviour toward wildlife (Teel and Manfredo, 2010). A cognitive hierarchy model has been developed to study the cognitive foundation of these relationships (Fulton et al., 1996; Whittaker et al., 2006; Manfredo, 2008; Teel and Manfredo, 2010). This theory is based on the value-attitude-behavior model (Homer and Kahle, 1988), focusing on the fact that cognition exists on different linked levels of abstraction. The cognitive 
hierarchy model includes values at the base, then going higher in the hierarchy VOs, attitudes and norms, behavioural intentions and behaviours. Values are the most abstract cognitions in the human mind, they are few in numbers, slow to change, central to beliefs and transcend to situations. The values of a person are shaped in the early years of life and are strongly influenced by the sociological context. Going up through the cognitive hierarchy, cognitions become more numerous, quick to change, peripheral and specific to situations. Value orientations are networks of basic and core beliefs that serve as intermediary between values and attitude (Manfredo, 2008). They are reflective of the cultural ideology (Manfredo et al., 2009) and provide a contextual meaning for values within a given domain of interest such as wildlife (Teel and Manfredo, 2010). Since they are less abstract than values, VOs can better explain specific thoughts and behaviours.

A first articulated classification of attitudes towards wildlife was proposed by Kellert (1980). In more recent years, the literature has suggested that people tend to show mainly two different and opposing VOs toward wildlife: mutualism and domination (Manfredo, 2008; Manfredo et al., 2009; Teel and Manfredo, 2010; Teel et al., 2010). A domination orientation stems from a utilitarian view of the relationship between humans and wildlife; it follows that wildlife should be managed for human benefit. Domination is one of the oldest VO showed by the humankind. A person with this VO tends to believe in the human mastery over the animals and is more prone to accept control measures resulting in death or harm to wildlife and more likely to engage in behaviours such as hunting and fishing. On the other hand, a person with a mutualism orientation tends to place humans and animals nearly on the same level; animals are seen as creatures with their own personalities and emotions. Such people recognize also that animals need care and have rights. A strong mutualism orientation render people less likely to accept control measures towards wildlife, as well as management options involving killing or hurting specimens but more likely to exhibit behaviors such as wildlife viewing and feeding. Mutualism is strongly related to the modernization, to the importance of wildlifes non-consumptive value and seems more consistent with a biocentric philosophy (Manfredo et al., 2016). The dualism mutualism-domination can be viewed in economic terms as utilitarian versus intrinsic views (Rolston III, 1983; Rolston, 1994). The dichotomy is usually seen as a continuum and the two different wildlife VOs often occurs in various levels. According to Teel and Manfredo (2010), gradients between these two main orientations can be found; in particular these authors suggest two other subclasses: distance and pluralism. The distant orientation includes people who do not care or who do not care very much about wildlife. On the other hand, pluralists do not show a particular orientation and their opinions on wildlife can be influenced by the contingent situation.

Several studies have demonstrated that wildlife VOs can serve as a predictor of attitudes toward wildlife (Hartel et al., 2015), wildlife management options (Kansky et al., 2016; Sponarski et al., 2015; Hermann et al., 2013; Jacobs et al., 2014), wildlife viewing (Manfredo et al., 2016; Teel et al., 2010) and toward hunting (Hrubes et al., 2001; Gamborg and Jensen, 2017) and fishing (Riepe and Arlinghaus, 2014). This body of research has shown that a specific behaviour towards wildlife can be explained by different VOs, and that VOs are at the basis of the conflicting attitudes for wildlife management actions, but none of these studies have used an economic approach. VOs can be linked to the economic theory of value as ideals affecting choices and actions. Steinhoff (1980) and subsequently Brown (1984) offered an interesting preference-related theory of value. They distinguish between held values and assigned values. A held value is the basis for preference about things, a 'conception of the preferable' (Brown 1984, p.232), a first order preference affecting second order preferences (i.e. choices and actions). Examples of held values provided by Brown are model of behaviour (e.g., bravery), end-states and qualities. In contrast, assigned values is the economic value of an object. Held values are values of the subjects and assigned values are of the objects. Within this framework, we can think about VOs as held values affecting WTP, i.e. economic values assigned to wildlife.

\section{Brief Overview of biodiversity in CE}

Non-market valuation techniques, and $\mathrm{CE}$ in particular, have been extensively used in valuing biodiversity. Most of the available studies do not focus on the economic valuation of biodiversity but rather on a single species (Pearce, 2001). For example, Han et al. (2010) implemented a CE survey, for assessing tourists' perceived best management alternative for the conservation of the goral, in Woraksan National Park (South Korea). Similarly, Hanley et al. (2003) evaluate the benefits provided by wild geese. Delibes-Mateos et al. 
(2014) considered the quantity of partridges likely to be shot in game activities as an attribute, while another attribute was the possibility to have additional (not specified) species. CE applications, in which several species are included in the study as different attributes, are less common in the literature. Hanley et al. (2010) evaluate simultaneously the worth of two Scottish species, namely hen harries and golden eagle, estimating people's WTP for an increase in their populations. Di Minin et al. (2013), investigate people's WTP for conserving several endangered species in South Africa, including lions, leopards, rhinos and buffaloes. Similarly, Wallmo and Lew (2011) evaluates the perceived benefits of conserving some marine species, currently under the stewardship of the National Marine Fisheries Service (NMFS) in the United States. Finally, Campbell et al. (2012) and Campbell et al. (2015) use a CE to estimate the existence value of a number of rare and endangered fish species in Ireland.

\subsection{The inclusion of attitudes and values in biodiversity evaluation studies}

While environmental attitudes are sometimes considered in CE surveys (see, among others, Choi and Fielding, 2013; Milon and Scrogin, 2006; Birol et al., 2006; Morey et al., 2008), and value orientations in contingent valuation under the Environmental Concern framework (Ojea and Loureiro, 2007; Spash, 2006), to be best of our knowledge VOs have never been included in choice experiments applied to biodiversity evaluation. Specifically Ojea and Loureiro (Ojea and Loureiro, 2007), in their Contingent Valuation study have tried to value the importance of three generic environmental VOs of the attitude towards the environmentthe altruistic, egoistic, and the biospheric value - in WTPs for the recovery of a marine bird, the common murre, in Galicia (Spain). Spash (Spash, 2006) have analysed the role of the same generic value orientations in estimating WTPs for wetlands recreation. The novelty of our study is that we have modeled specific latent value orientation to explain taste heterogeneity of respondents towards wildlife conservation in a CE.

As already highlighted, including attitudes in the utility function may not represent an optimal solution. In particular, measurement errors may occur. In addition, attitudinal questions may be correlated with other unobserved characteristics of the respondent, thus causing correlation between the deterministic and stochastic components of the utility. In an attempt to address this important issue, hybrid models have been recently developed (Ben-Akiva et al., 1999, 2002; Bolduc et al., 2005). The innovative approach is to use latent variables to explain attitudes and psychological constructs. The latent variable is a function of socio-demographic characteristics and enters the model both in the choice model and as explanatory variable for attitudinal questions (Bolduc and Alvarez-Daziano, 2010). In this way, attitudinal questions are treated as a function of the latent variable, eliminating endogenity problems. Hybrid choice models have been applied extensively in transportation research (see, among others, Daly et al., 2012; Abou-Zeid et al., 2010; Hess et al., 2013), to lesser extent in other fields. In environmental valuation, an example of application is given by the paper of Hess and Beharry-Borg (2012), which analyzes values of improving the quality of coastal water. Another interesting paper is provided by Hoyos et al. (2015), in which the authors use a psychometric scale, called awareness of consequences (AC), in order to understand choices of respondents while valuing land-use policies for Natura 2000 network sites. Finally, a hybrid approach to include environmental attitudes for valuing forest ecosystem services has been recently proposed (Agimass et al., 2017). In this paper, we make use of two latent variables, one describing the mutualism orientation and one for the dominant orientation. Following the idea of Hoyos et al. (2015), latent variables enter the model in the class allocation function of the latent class model.

\section{Methods}

\subsection{Study Area}

Data for this case study originated from a questionnaire survey, administrated face-to-face in Trentino, a mountainous province in the north- east of the Italian Alps. Trentino is an important tourist destination, with around three million tourists per year and a good balance between winter and summer tourists. This area is important for nature conservation, because of the presence of several rare and endangered species. The province includes one national park (Parco Nazionale dello Stelvio), two regional parks (Adamello-Brenta and Paneveggio Pale di San Martino) and several other Natura 2000 sites, occupying 34 percent of the total area. Among several interesting species, this study focuses on tourists' preferences for conserving the wolf 
(Canis lupus Linnaeus), the lynx (Linx linx) and the salamander of Aurora (Salamandra atra aurorae), a rare subspecies of the alpine salamander. Wolf and lynx, extinct in Trentino around the end of the 19th century, naturally came back from neighbouring areas, in particular the wolf from the Italian Appennine and the lynx from Switzerland. At present, there are seven wolves and only one lynx in the regional area, therefore the population size is not enough to assure the survival of the species. The salamander of Aurora, conversely, is a rare amphibious living only in a limited area of the Province with a population of about ten specimen.

\subsection{Data}

The CE survey was carried out by means of personal interviews, conducted by three trained interviewers, to a sample of tourists of the Province of Trento from July and September 2015. We focused on tourists as they comprise a large share of the direct users of the parks and natural areas in Trentino. Wildlife is an important regional resource and attracts many visitors annually (Tattoni et al., 2017). We also acknowledge that local communities represent a relevant actor for wildlife management and should be considered in decision-making, but this important issue was out of the scope of the present research. Respondents were randomly selected in tourist areas and invited to take part to the interview. Personal interviews were believed to facilitate the "yes-saying", however recent contributions suggest that administration method do not influence SP surveys (Bell et al., 2011; Lindhjem and Navrud, 2011), even though results are mixed. The NOAA panel on contingent valuation suggested personal interview as administration method (Arrow et al., 1993), while the most recent SP guidelines (Johnston et al., 2017) do not provide specific recommendations. We therefore chose to administrate interviews personally. Moreover, some authors argue that stated CE have the advantage to reduce the yeah-saying behaviour compared to contingent valuation surveys (among others, Boxall et al., 1996; Hanley et al., 1998; Winslott Hiselius, 2005). A pilot study with 63 tourists was conducted in June 2015 to fine-tune the questionnaire, check attributes and levels and collect priors to be used for generating a Bayesian D-efficient design (Bliemer et al., 2008). The questionnaire was composed by 34 questions, organized in four thematic sections. The questionnaire was a tool used for a broader research and not all questions were considered in this study. In section number one, environmental indicators for the individual VO were collected with fourteen propositions, to which respondents had to express their degree of agreement on a 7-point-Likert scale. These questions replace the typical attitudinal questions that are included in stated preferences applications. Statements to capture orientations were taken from the questionnaire used by Sponarski et al. (2015) and previously by Teel and Manfredo (2010), which were exactly replicated to better capture orientations. Out of these, seven propositions were related to the mutualism orientation and seven to the domination orientation. Attitudinal questions in the form of Likert scales might be subject to acquiescence, i.e. yeah-saying bias (Ray, 1990), because people might tend to show a more 'environmentally-friendly' attitude compared to their real values. For this reason, we tried to reduce the occurrence of yeah saying bias by training interviewers to be as neutral as possible while administrating the questionnaire and allow people self-filling in the answers to VOs questions. Although questions were taken from the literature and already tested, we also checked wordings and consistency during the pre-test phase. The inclusion of fourteen proposition to examine VOs was necessary to respect prescription from the environmental psychology literature (Manfredo, 2008; Teel and Manfredo, 2010; Sponarski et al., 2014), however, using all these pieces of information into the choice model would have complicated too much the estimation, in terms of number of parameters. For this reason, only four were selected as indicators for the final hybrid model (Table 1). This simplification is convenient because it reduces the number of parameters, which was already large, but it might approximate the assessment of individual orientation. The inclusion of four indicators is in line with several hybrid CE studies (for example, Hess and Stathopoulos, 2013; Hoyos et al., 2015). In the final model, we included the four statements that interviewers reported to be the most clear for respondents, however we also conducted a sensitivity analysis using different set of statements and results did not change significantly. Section number two contained questions on emotions provided by respondents in their interactions with wildlife. These questions were not related to VOs and were not considered in this study. Section three contained choice cards which were preceded by an explanatory text that was read by interviewers before showing the cards. Respondents were informed that wolves, lynx and salamanders of Aurora are protected and managed in Trentino from the Province of Trento and from the natural 

parks within specific European projects. Then they were informed about the actual situation ( 7 wolfes, 1 lynx and 10 salamander) and we explained that the actual situation can improve, but also deteriorate if no management actions are going to be taken. We gave no description of any management actions. The null alternative was presented to respondents as the 'do-nothing situation' in terms of management, what will happen if management actions are not implemented. We then added that an entrance fee for the park might be a solution to increase revenues and address conservation issues. Finally, we included some cheap talks to inform respondents that results will be used by the Province of Trento to improve management policies and to encourage accurate responses. Cheap talks were remainders that they had to consider their budget and that if they agreed to pay a fee they would have less money for other purchasings. The preparation of the CE was carried out following guidelines available in the literature (Hoyos, 2010; Riera et al., 2012). The attributes selected for the survey, as shown in table 2, are the number of animals for wolves, lynx and salamanders; the cost attribute was an entrance fee for parks and natural areas in Trentino. At present, there are no entrance fees and visitors can access all natural areas for free, therefore our payment veichle is hypothetical. However a ticket could be a solution to increase parks' self-funding. In fact, in Trentino, parks have to co-finance activities related to biodiversity conservation, thus an entrance fee was included as a way for tourists to contribute to these actions. Attributes and attribute levels were determined by experts and scientists. In one-on-one interviews wildlife managers of the Province of Trento and zoologists of the Science Museum of Trento stated that a viable population for wolves and lynx was of about 45-50 individuals and a maximum of 90-100. Within this range the carrying capacity of the territory is respected and wolves and lynx are expected not to compete for habitat and food. Salamanders could potentially have a bigger population, but the pre-test highlighted that larger levels lead people to think the animal was not in danger and non-attendance of this attribute was high. Therefore, we decided to maintain the same attribute levels also for salamanders. Despite experts proposed levels for animal populations that are respectful of the local carrying capacity, there could be correlation across attributes if some management actions are proposed. For example, if we stated that larger populations had to be achieved by an increase in the habitat quality, this would imply a better ecosystem for all the animals and their population would increase simultaneously. For this reason, we were careful in avoiding management suggestions, so that we were able to capture uncorrelated preferences for each of the species ${ }^{1}$. During the pre-test phase we also asked some questions that can be used to understand whether respondents perceived attributes to be correlated. For this purpose, we asked respondents their opinion on the current size of the populations of wolves, lynx and salamanders. Since most of the respondents reported high numbers of animals and thought that the populations were increasing, this brings additional evidence that respondents, on average, did not perceive particular problems in the coexistence of the animals.

After the pre-test we noticed that there was a quite large share of preferences for the null alternative, which was chosen $20.5 \%$ of the time as first best and $7.7 \%$ of the time as second best. This result, together with a previous experience on wildlife study in the same study area, which also detected a large share of SQ choices (Agnolin, 2012), led us to worry for the SQ bias. The SQ coefficient was positive, suggesting positive utility for the current situation. We suspected that using the real SQ led people to be more likely to choose it, because they could have a certain number of animals without paying for them. In this way policy improvements provided by larger population sizes were not properly highlighted, therefore we opted for a null alternative (Olsen et al., 2012; Whittington et al., 2017; Scarpa et al., 2011), which is often used in the literature and contributed to improve the model $^{2}$. We believe that this does not impact on final estimates, as our objective was to estimate marginal WTP and not consumer surplus, for which a hypothetical SQ could have caused problems when applying the log-sum formula (Hanemann, 1984), because the comparison of the policy improvement with the baseline SQ would be complicated.

\footnotetext{
${ }^{1} \mathrm{~A}$ small effect of correlation between attribute levels might still be present and this is a limitation to consider when interpreting the results.

${ }^{2}$ As one reviewer suggested, in our experiment part of the SQ bias could be caused by the payment vehicle we chose, as an entrance ticket could be opposed by tourists. However, a different mandatory instrument was difficult to retrieve and voluntary payments are often inadequate as they tend to overestimate the WTP (Wiser, 2007). We believe that this effect is likely to be small, because paying a fee for a natural park is expected by the new law on natural areas (art. 18 L. 394/91).
} 


\begin{tabular}{|c|c|c|}
\hline & Question & Orientation \\
\hline WVO1 & $\begin{array}{l}\text { We should strive for a world where } \\
\text { theres an abundance of wildlife for } \\
\text { hunting }\end{array}$ & Domination \\
\hline WVO2 & $\begin{array}{l}\text { The needs of humans should take prior- } \\
\text { ity over fish and wildlife protection }\end{array}$ & Domination \\
\hline WVO3 & $\begin{array}{l}\text { We should strive for a world where hu- } \\
\text { mans and fish and wildlife can live side } \\
\text { by side without fear }\end{array}$ & Mutualism \\
\hline WVO4 & $\begin{array}{l}\text { I value the sense of companionship I re- } \\
\text { ceive from animals }\end{array}$ & Mutualism \\
\hline \multicolumn{3}{|c|}{ Table 1: Questions on value orientations } \\
\hline & \multicolumn{2}{|l|}{ Table 2: Attributes and levels in the choice tasks } \\
\hline Attribute & Description & \\
\hline Wolves & \multicolumn{2}{|c|}{$0,15,30,45,60,75,90$} \\
\hline $\operatorname{Lin} x$ & Number of lynx & $0,15,30,45,60,75,90$ \\
\hline Salamanders & Number of salamanders & \\
\hline Cost & Entrance fee for parks (in $€) \quad 0,3,6,9$ & $\begin{array}{l}0,15,30,45,60,75,90 \\
0,3,6,9,12,15,18\end{array}$ \\
\hline
\end{tabular}

We hypothesized a non-linear relationship between population sizes and people's WTP. People might be willing to pay for a viable population but, at the same time, they might want not too big populations because they may generate human-wildlife conflicts (Dickman, 2010; Kubo and Shoji, 2014). For this reason, we tested non-linearities in the utility with two models, one with a linear specification of the utility function with a dummy for each attribute level (with twenty parameters to be estimated) and a quadratic specification (with eight parameters), with a linear and quadratic coding for each attribute, in a multinomial logit model. The log-likelihood were very similar (-5300 in the linear model and -5335 in the quadratic model) but the BIC was lower for the quadratic model. For this reason, we decided to use the quadratic expression of the utility function also in the more complicated subsequent models, which has also the advantage of a smaller number of parameters to be estimated. The monetary attribute was linearly coded.

Each respondent was asked to complete twelve choice tasks, composed by a null alternative and two other alternatives. The chosen answer format was the best-worst scaling (BWS) (Flynn et al., 2007), through which each interviewed person had to express his/her best and worst alternative, among the three available. The BWS assures accurate estimates and provides a larger number of observation compared to the common pick one solution, with only a small effort increase for respondents. An example of choice card is provided in figure 1. The final section of the questionnaire included the usual socio-demographic characteristics (e.g., gender, age, education and income). For the present analysis, the relevant population was assessed to be composed by tourists in the province, aged 18 or more, which were reached and surveyed on site.

\subsection{Econometric Analysis}

We implement a hybrid latent class and latent variable model, following the method proposed by Hoyos et al. (2015). Value orientations towards wildlife are considered to be a source of taste heterogeneity among respondents but they are, at the same time, latent and unobservable. Some of the latent orientations may be captured by socio-demographic characteristics. Such underlying individual VOs influence choices, through class allocation probabilities, and answers to VOs questions value at the same time. Within this hybrid framework, two set of structural equations have to be specified, one related to the choice model and one to the latent variable model. In addition, a set of measurement equations has to be included as well. Measurement equations include answers to VOs questions as dependent variables, explaining their outcome with the latent variable as covariate.

Concerning the choice model, the theoretical foundation lies in the theory of random utility (RUM), which 
Figure 1: Example of choice card

\begin{tabular}{|c|c|c|c|c|}
\hline & & Scenario A & Scenario B & Scenario $\mathrm{C}$ \\
\hline 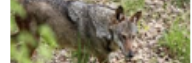 & Number of free wolves & 90 & 30 & 0 \\
\hline & Number of free lynx & 0 & 45 & 0 \\
\hline & $\begin{array}{l}\text { Number of free } \\
\text { salamander aurora }\end{array}$ & 45 & 0 & 0 \\
\hline$\approx$ & Entrance ticket & $6 €$ & $12 €$ & $0 €$ \\
\hline \multicolumn{2}{|c|}{ Choose your most preferred option (mark $\sqrt{ }$ ) } & & & \\
\hline Choose your leas & preferred option (mark $\sqrt{ }$ ) & & & \\
\hline
\end{tabular}

allows defining the observed part of the utility through a statistical model (Manski, 1977). According to RUM, the utility that respondent $n$ derives from alternative $i$ in the choice situation $t$ is given by:

$$
U_{\text {int }}=V_{\text {int }}+\epsilon_{\text {int }}
$$

where $V_{\text {int }}$ is the observed component of the utility, while $\epsilon_{i n t}$ represents the non-observed random disturbance. The observed component of the utility $V_{i n t}$ is described by a set of attributes $x_{i t}$ and by a vector of parameters $\beta$, indicating the marginal effect of the attributes on utility. Modelling utility needs assumptions on the distribution of the random term $\epsilon$. A common approach is to assume an i.i.d. type I extreme value distribution for the random term, thus leading to a multinomial logit model (MNL). The MNL model assumes preferences are constant across respondents and does not take into account preference heterogeneity. In order to account for preference heterogeneity, we make use of an extension of the simple MNL, the latent class logit model (LC), which hypothesise that individuals can be sorted into $C$ classes (Greene and Hensher, 2003), each with class-specific $\beta_{c}$. Preferences are now constant in each class but vary across classes, thus relaxing the assumption of preference homogeneity in the entire sample.

In the LC framework, given class membership $c$, the probability of a sequence of $T_{n}$ choices made by individual $n$ is given by (Shen, 2009):

$$
\operatorname{Pr}\left(y_{n} \mid \beta_{c}, x_{n}, c\right)=\prod_{t=1}^{T_{n}} \frac{\exp \left(\beta_{c}^{\prime} x_{i n t}\right)}{\sum_{j=1}^{J} \exp \left(\beta_{c}^{\prime} x_{j n t}\right)},
$$

where $y_{n}$ is the choice made over the total number on choice situations $T_{n}$ and $J$ is the number of alternatives in each choice situation ${ }^{3}$.

The second structural set of equations concerns the latent variables. We include two latent variables, one capturing the domination behaviour, while the second capturing the mutualism behaviour. Reference categories are distant and pluralist, because indicators for these categories are not available Teel and Manfredo (2010). The $q$ th latent variable is defined as:

$$
L V_{q n}=h\left(Z_{n}, \gamma_{q}\right)+\omega_{q n}
$$

\footnotetext{
${ }^{3} \mathrm{~A}$ latent class model is also advantageous since it inherently allows for possible correlations between preferences for different attributes as well as how attributes were perceived by respondents
} 
Table 3: Explanatory variables used in the latent variable equations

\begin{tabular}{ll}
\hline Latent Variable variables & Description \\
\hline Female & $1=$ female \\
& $0=$ otherwise \\
AGE_category1 & $1=18<$ AGE $<30$ \\
& $0=$ otherwise \\
AGE_category2 & $1=31<$ AGE $<45$ \\
& $0=$ otherwise \\
AGE_category3 & $1=46<$ AGE $<60$ \\
& $0=$ otherwise \\
\hline
\end{tabular}

where $h\left(Z_{n}, \gamma_{q}\right)$ is the deterministic part of the equation; $Z_{n}$ is a vector of sociodemographic characteristics and $\gamma_{q n}$ a vector of parameters to be estimated; $h($.$) is linear. Conversely, \omega_{q n}$ is the error component of the equation, which is assumed to follow a normal distribution with zero mean and standard deviation $\sigma_{q \omega}$. As visible in table 3 , covariates in the latent variable equations were gender and age classes, using the highest age class (i.e. people aged 60 years or above) as reference level.

Together with the described two structural equation sets, a measurement equation set of variables has to be determined as well. The measurement equation set is composed by the answers to VOs questions as dependent variable, explained with the latent variable as covariate. The $l$-th indicator for respondent $n$ is

$$
I_{q n l}=f\left(L V_{q n}, \xi_{q}\right)+\nu_{q n}
$$

Where $I_{q n l}$, i.e. the answer to $\mathrm{VO}$ questions, is a function of the latent variable $L V_{q n}$ and the vector of parameters to be estimated $\xi_{q}$. Value orientation questions were collected on a seven point scale (from strongly disagree to strongly agree), subsequently recoded in a three level scale. Categories "strongly disagree" and "disagree" were merged together and recoded as one, median classes ("mildly disagree", "neutral" and "mildly agree") were coded as two and "agree" and "strongly agree" were coded as three. This should not modify the result as the order of preference is maintained. This question format has an intrinsic ordering of the answers, thus an ordered logit model has been used for modelling the measurement equations. Ordered logit includes threshold parameters for the latent variable (Greene, 2003), which need to be estimated:

$$
f(x)=\left\{\begin{array}{rr}
i_{1} & \text { if }-\infty<L V_{q n}<\tau_{q l 1} \\
i_{2} & \text { if } \tau_{q l 1}<L V_{q n}<\tau_{q l 1}+\delta q l 1 \\
\ldots & \\
i_{k} & \text { if } \tau_{q l(k-1)}<L V_{q n}<\infty
\end{array}\right.
$$

where $\tau_{q l 1}$ is the first threshold parameter and $\delta_{q l}$ the width of each ordered class. The latent variables $L V_{1 n}, \ldots, L V_{Q n}$ are linked to the choice model as well and enter the class allocation probabilities $\pi_{n, c_{s}}$, that are now respondent specific because of the influence of the latent variables. During the modelling phase we also explored the possibility to include only one latent variable, entering the model as explanatory variable for two indicators. We tried this for both the mutualism and dominant latent variable. Signs were all maintained, in the choice part of the model coefficients changes only after the fourth decimal place, suggesting that using one or two latent variables does not impact the computation of WTP significantly. We then decided to include in the final model both the mutualist and dominant LVs to show the effect of the two types of orientations at the same time. The described equations are estimated simultaneously, by jointly maximizing the likelihood function of the sequence of choice and the answer to attitudinal questions, conditional on the realization of the latent variable $L V_{q n}$. The log-likelihood function of the model is given by the integration over $\omega_{q n}$ :

$$
L L(\beta, \mu, \gamma, \xi, \tau)=\sum_{n=1}^{N} \ln \int_{\omega}\left(P_{n} \prod_{l=1}^{L_{q}} \prod_{q=1}^{Q} L_{I q l n}\right) g(\omega) d
$$




\begin{tabular}{llll}
\hline Orientation & Disagree & Median & Agree \\
\hline WVO1 & $42.62 \%$ & $44.76 \%$ & $12.62 \%$ \\
WVO2 & $35.48 \%$ & $41.66 \%$ & $22.86 \%$ \\
WVO3 & $3.58 \%$ & $23.57 \%$ & $72.85 \%$ \\
WVO4 & $2.38 \%$ & $22.62 \%$ & $75.00 \%$ \\
\hline
\end{tabular}

Table 4: Level of agreement with orientation questions of the respondents

Sobol sequences for the simulation of the error term of latent variable.

\section{Results and Discussions}

Interviewers were able to collect a sample of 420 respondents (65 percent response rate); however, only 341 were useful for the present analysis, for a total number of 8184 observations. Respondents were on average 43 years old and females accounted for the 53.3 percent of the sample (males constituted the remaining 46.7 percent). Most of respondents had a high school degree (41 percent) but the presence of people with a university diploma was high as well (around 37 percent). Sample characteristics are in line with the average tourists visiting Trentino, although we oversampled a bit national tourists compared to foreigners. In fact, according to local statistics on tourism ${ }^{4}$ summer visitors from abroad represent $26 \%$ of the total, while in our sample they accounted for $10.3 \%$. (35 respondents)

Answers to questions on VOs are available in table 4, in which WVO1 and WVO2 are questions related to the domination orientation, while WVO3 and WVO4 are connected with the mutualism orientation. It is possible to see that most of respondents tend to disagree with the propositions related to the domination orientation and to agree more with the mutualism propositions, thus suggesting that most of respondents show a mutualism orientation. A paper by Vaske et al. (2011), which reports a study in the Netherlands, found that $44 \%$ of respondents showed mutualism, $21 \%$ a dominant orientation and $35 \%$ none of the two. They also pointed out that their sample was mainly composed by people living close to natural areas and that there is a dichotomy between urban and rural residents, with people living in rural areas to be more in favour of an anthropocentric mentality, involving hunting and the use of wildlife for people's benefit Teel and Manfredo (2010). Looking at the frequency of responses in our sample, the share of mutualist people seems to be larger and the place of origin of local tourists might explain the result. In fact, only $11 \%$ of respondents lived in rural territories while the vast majority lived in urban areas (34\% in small town and $45 \%$ in medium of large cities). Part of this result might be caused by acquiescence but, more importantly, results might be driven by the different reference population between the cited study and this one, which is focused on tourists. Tourists usually visit natural areas for short periods, so their psychological distance with wildlife is larger. Serenari et al. (2015) explored the differences in wildlife value orientations among visitors, local and tourists, to Chiles Tamango National Reserve. They found that local residents were more likely to belong to the mixed protectiongroup ( $57.6 \%$ of residents), while tourists to the strong protections group $(73.4 \%$ of tourists). Tourists were more supportive of huemul conservation policies and were also more likely to pay the reserve entry fee.

The large share of people with high scores in the mutualist orientation statements, as well as small shares of agreement with dominant orientation statements confirms a societal shift from dominance to mutualism, which is a result of modernization (Manfredo, 2008; Manfredo et al., 2009, 2016). We conducted a $\chi^{2}$ test to check the association between the four orientation propositions. All tests were significant at one percent confidence level ( $\mathrm{p}$-value $=0.002$ and $\mathrm{p}-$-value $=0.000$, respectively), thus the null hypothesis of independence between answers was rejected. This result strengthens the idea that answers to domination and mutualism

${ }^{4}$ http://www.statistica.provincia.tn.it/binary/pat_statistica_new/turismo/ITuristiNellaStagioneEstiva2015. 1447238555.pdf 
Table 5: Coefficients for the specification of latent variables

\begin{tabular}{llll}
\hline Domination LV & & & \\
\hline Parameter & Estimate & St. err. & sign. \\
\hline Constant & 7.57 & 1.09 & $* * * *$ \\
Female & $-1.97 \cdot 10^{-01}$ & $7.91 \cdot 10^{-01}$ & \\
AGE_category1 & -8.12 & 1.01 & $* * * *$ \\
AGE_category2 & -6.87 & 1.26 & $* * *$ \\
AGE_category3 & -8.56 & $6.29 \cdot 10^{-01}$ & $* * * *$ \\
$\omega_{\text {dom }}$ & 7.07 & $7.90 \cdot 10^{-01}$ & $* * * *$ \\
\hline Mutualism LV & & & \\
\hline Parameter & Estimate & St. err. & sign. \\
\hline Constant & 1.53 & $4.61 \cdot 10^{-01}$ & $* * * *$ \\
Female & $2.24 \cdot 10^{-01}$ & $2.23 \cdot 10^{-01}$ & \\
AGE_category1 & $-4.75 \cdot 10^{-01}$ & $5.82 \cdot 10^{-01}$ & \\
AGE_category2 & $6.81 \cdot 10^{-01}$ & $5.92 \cdot 10^{-01}$ & $*$ \\
AGE_category3 & $3.36 \cdot 10^{-01}$ & $5.66 \cdot 10^{-02}$ & $* * *$ \\
$\omega_{m u t}$ & -1.75 & $7.59 \cdot 10^{-01}$ & $* *$ \\
\hline$* * * *$ \\
\multicolumn{2}{c}{$0.001,{ }^{* * *}$} & $p<0.01,{ }^{* *} p<0.05,{ }^{*} p<0.1$
\end{tabular}

are statistically associated. Measurement equations, linking latent variables to VO questions, are displayed in table 6. Even in this system of equations, it is possible to see that coefficients associated with the latent variable $(\xi)$ are always statistically significant, meaning that latent variables have explanatory power for modelling VOs.

Table 5 displays coefficients for the latent variables, which are assumed to depend on gender and age. Differences in coefficients between the two latent variables indicate that they both have a role and explain dissimilarities between mutualism-dominance and other orientations, such as distance and pluralism. LVs enter the class allocation function, therefore signs indicate the probability of belonging to class one (for identification reason, we set parameters for class two fixed at zero (Scarpa and Thiene, 2005)). The coefficient for females is positive in the mutualism latent variable, while negative for the domination orientation. This means that, all else held constant, females have a higher likelihood of having a mutualism orientation, albeit neither are statistically significant. Difference in signs is also visible for the dummy variables indicating age classes. The baseline age class is given by respondents who are 60 years of age or over. Thus, in the domination latent variable, the negative and statistically significant coefficients indicate that people younger than the baseline are less likely to show a domination orientation. In contrast, age categories 2 and 3 are significant in the mutualism latent variable, but not class 1 . Thus, the general indication from our model is that younger tourists are more likely to be mutualist, rather than older ones, all else held equal. A negative relationship between age and interest towards wildlife is a quite common result and found, for example, by Bjerke et al. (1998). In the broader context of environmental protection, two main reasons have been detected for such a result: first, older people have less time to benefit from long-term preservation of the resources (Carlsson and Johansson-Stenman, 2000). Secondly, younger people are often found to be more concerned about environmental problems (Howell and Laska, 1992).

Table 7 reports the results of a latent class model and the hybrid latent class and latent variable model, both of which are specified having two latent classes. The first model is considered the baseline for our analyses. The share of SQ as first choice was roughly $4 \%$ and only seven people out of 420 systematically chose the SQ alternative over the 12 choice tasks, therefore protest responses do not seem to be a problem for the survey. In both classes the cost coefficient is negative, which is expected and in line with the economic theory, because it is an indication that, all else being equal, as the cost increases utility decreases. Nevertheless, we note that it is statistically significant only in the second class. In the first class, coefficients for the population of animals is always positive, thus meaning that people are willing to contribute to actions 
Table 6: Results of the orientation questions

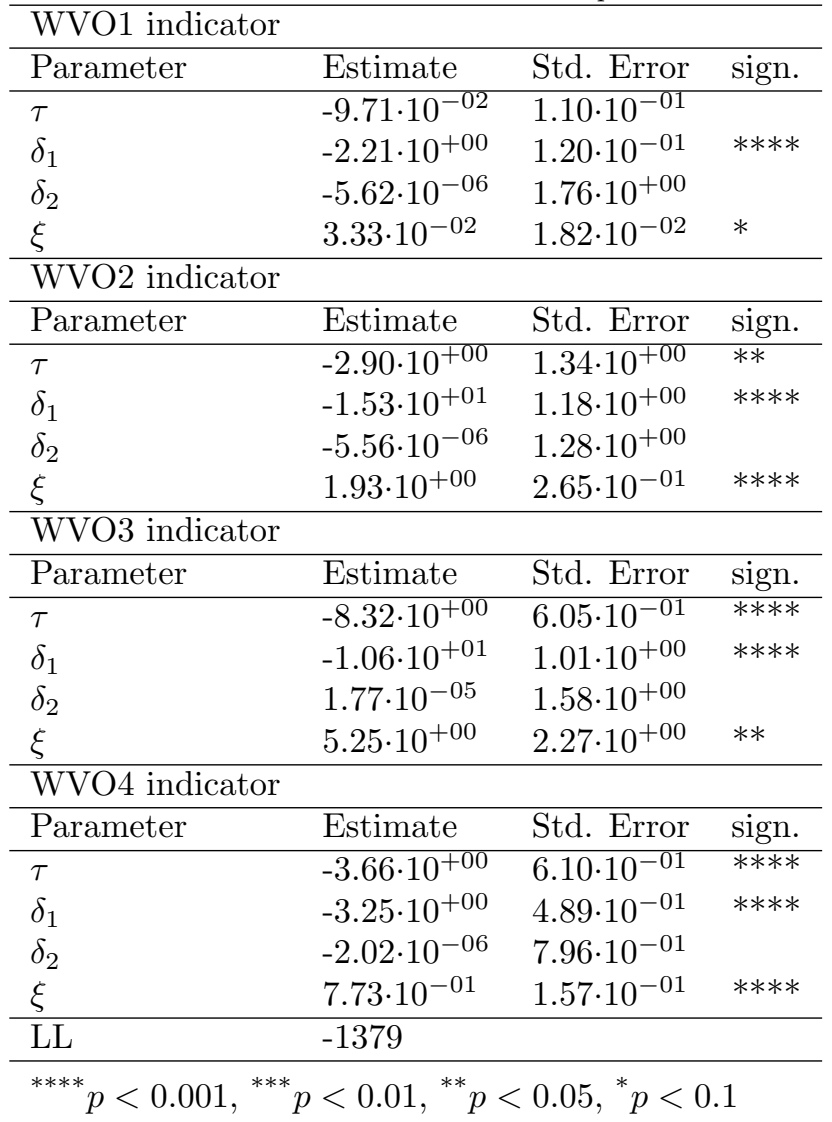

for their conservation. Conversely, the coefficients associated with quadratic number of animals is negative. This result indicates a concave relationship between individuals' utility and number of specimen in the animal populations.

In class number one, significance levels of the estimated parameters is rather poor. In fact, only the ASC coefficient is statistically significant at $5 \%$ level. In this class, respondents seem not interested to increase the population of wolves, lynx and salamanders. Probably, the insignificance of parameters is due to the fact that in this class members do not care much about wildlife. In the second class, the trend is different in terms of significance, the estimated parameters are in fact almost all statistically different from zero. The magnitude of the coefficients is slightly different, indicating different marginal utilities (and perhaps differences in scale) compared to the first class. In general, this model does not appear to be fully satisfactory. Class allocation is only given by a constant term and it does not appear to be appropriate to model heterogeneity in answers. Probably, a simple two class model that does not recognize latent attributes of value orientation is not adequate for explaining preference heterogeneity across respondents. Class probabilites were assessed to be 34 percent for class number one and $66 \%$ for class number two.

We now move to the hybrid model. The log-likelihood function of the choice component of the model is higher, suggesting a better fit of the choice data. Similarly, AIC and BIC are smaller than those of the simple latent class. Cost coefficients are negative in both classes, as in the baseline model, but, importantly, are now found to be statistically significant in both classes. In general, it can be observed that the sign of coefficients are the same as in the baseline model, only their magnitude changes. The number of statistically significant parameters is higher. The latent variables for the mutualism orientation was found to have a significant effect in class allocation. This result suggests that the underlying VO has a good explanatory power for determining class membership and therefore preference heterogeneity for the populations of wolves, lynx and salamanders. The coefficient expressing the effect of the mutualism latent variable is negative, suggesting that 
Table 7: Results of the 2 class model and the 2 class hybrid model

\begin{tabular}{|c|c|c|c|c|}
\hline & \multicolumn{2}{|c|}{ Latent class } & \multicolumn{2}{|c|}{ Hybrid model } \\
\hline Parameter & Estimate & Std. Error & Estimate & Std. Error \\
\hline Wolf.c1 & $5.51 \cdot 10^{-3}$ & $2.38 \cdot 10^{-2}$ & $2.82 \cdot 10^{-2}$ & $1.28 \cdot 10^{-2} * *$ \\
\hline Wolf ${ }^{2} . c 1$ & $-5.90 \cdot 10^{-5}$ & $1.97 \cdot 10^{-4}$ & $-3.28 \cdot 10^{-4}$ & $1.11 \cdot 10^{-4} * * *$ \\
\hline $\operatorname{Lin} x . c 1$ & $2.53 \cdot 10^{-2}$ & $2.00 \cdot 10^{-2}$ & $4.10 \cdot 10^{-2}$ & $1.54 \cdot 10^{-2} * * *$ \\
\hline $\operatorname{Lin} x^{2} . c 1$ & $-2.51 \cdot 10^{-4}$ & $1.99 \cdot 10^{-4}$ & $-4.19 \cdot 10^{-4}$ & $1.44 \cdot 10^{-4} * * *$ \\
\hline Salam.c1 & $1.78 \cdot 10^{-3}$ & $8.70 \cdot 10^{-3}$ & $6.04 \cdot 10^{-3}$ & $1.08 \cdot 10^{-2}$ \\
\hline Salam $^{2} . c 1$ & $-4.70 \cdot 10^{-5}$ & $7.48 \cdot 10^{-5}$ & $-7.91 \cdot 10^{-5}$ & $9.85 \cdot 10^{-5}$ \\
\hline Cost.c1 & $-2.99 \cdot 10^{-2}$ & $1.89 \cdot 10^{-2}$ & $-8.80 \cdot 10^{-2}$ & $2.03 \cdot 10^{-2} * * * *$ \\
\hline Asc.c1 & -1.24 & $4.25 \cdot 10^{-1} * * *$ & $-5.64 \cdot 10^{-2}$ & $6.83 \cdot 10^{-1}$ \\
\hline Scale.c1 & 1.09 & $5.06 \cdot 10^{-1 *}$ & $6.23 \cdot 10^{-1}$ & $4.04 \cdot 10^{-1}$ \\
\hline Wolf.c2 & $8.79 \cdot 10^{-2}$ & $1.74 \cdot 10^{-2} * * *$ & $5.32 \cdot 10^{-2}$ & $5.30 \cdot 10^{-3} * * * *$ \\
\hline Wolf ${ }^{2} . c 2$ & $-9.55 \cdot 10^{-4}$ & $2.96 \cdot 10^{-4} * *$ & $-5.43 \cdot 10^{-4}$ & $4.66 \cdot 10^{-5} * * * *$ \\
\hline Linx.c2 & $5.27 \cdot 10^{-2}$ & $2.14 \cdot 10^{-2} *$ & $4.95 \cdot 10^{-2}$ & $4.94 \cdot 10^{-3} * * * *$ \\
\hline $\operatorname{Lin} x^{2} \cdot c 2$ & $-5.49 \cdot 10^{-4}$ & $1.85 \cdot 10^{-4} * *$ & $-4.85 \cdot 10^{-4}$ & $4.59 \cdot 10^{-5} * * * *$ \\
\hline Salam.c2 & $1.87 \cdot 10^{-2}$ & $9.83 \cdot 10^{-3 *}$ & $1.65 \cdot 10^{-2}$ & $4.39 \cdot 10^{-3} * * * *$ \\
\hline Salam $^{2} . c 2$ & $-1.17 \cdot 10^{-4}$ & $9.87 \cdot 10^{-5}$ & $-1.49 \cdot 10^{-4}$ & $4.17 \cdot 10^{-5} * * * *$ \\
\hline Cost.c2 & $-1.58 \cdot 10^{-1}$ & $7.73 \cdot 10^{-2} * *$ & $-9.00 \cdot 10^{-2}$ & $8.87 \cdot 10^{-3} * * * *$ \\
\hline Asc.c2 & -5.50 & $7.70 \cdot 10^{-1} * * * *$ & -5.27 & $9.62 \cdot 10^{-1} * * * *$ \\
\hline Scale.c2 & $5.33 \cdot 10^{-1}$ & $3.02 \cdot 10^{-1} *$ & $9.07 \cdot 10^{-1}$ & $1.33 \cdot 10^{-1} * * * *$ \\
\hline class_constant & $6.469 \cdot 10^{-1}$ & $3.958 \cdot 10^{-1}$ & 7.48 & $2.36 * * *$ \\
\hline LV_dom.cl1 & & & -2.92 & 1.83 \\
\hline LV_mut.cl1 & & & $-4.33 \cdot 10^{1}$ & $2.58 \cdot 10^{-1} * * * *$ \\
\hline LL (choice model) & & -4147 & & -4013 \\
\hline LL (global) & & -4147 & & -4333 \\
\hline $\mathrm{AIC}$ & & 8332 & & 8024 \\
\hline $\mathrm{BIC}$ & & 8465 & & 8017 \\
\hline Observations & & 8184 & & 8184 \\
\hline Respondents & & 341 & & 341 \\
\hline
\end{tabular}

respondents with a mutualism orientation are more likely to belong to the second latent class. Coefficients in this class are larger than class number one, indicating that increasing the number of animals provides higher utility for people in this class. This is also reflected in larger WTPs for the three animals, which will be discussed later. This result was anticipated, because people showing mutualism are expected to be willing to pay more than dominants for wildlife conservation. Prior research suggested that VOs may be predictors of attitudes towards wildlife and wildlife management options; our study suggests that VOs may also influence the economic behaviour of the individual.

Concerning welfare measures, the quadratic coding for the number of animals of each species allowed a non-linear representation of WTP levels for each population size, expressed per person per visit to one of the regional park. The calculation of WTPs was computed by means of the following formula:

$$
W T P_{n}=\frac{-\left(\beta * n+\beta * n^{2}\right)}{\beta_{\text {cost }}}
$$

where $n$ is the population size of the species of interest, while $\beta$ and $\beta_{\text {cost }}$ are, respectively, the estimated coefficients from the choice model for the species of interest and the cost attribute. Table 8 shows estimated WTP with confidence intervals for some representative sizes of the populations. Results of the WTP computation per each animal is shown in figures 2, 3 and 4, together with the confidence intervals calculated through the Krinsky-Robb method, using 5,000 draws (Hole, 2007). WTP is presented separately for the two classes. The continuous lines represents the mean class--specific marginal WTP, while dashed lines the lower 


\begin{tabular}{cc|ccc|ccc}
\hline & & \multicolumn{3}{c|}{ Class one } & \multicolumn{3}{c}{ Class two } \\
\hline Animal & $\mathrm{N}$ & Lower & Mean & Upper & Lower & Mean & Upper \\
\hline \multirow{4}{*}{ Wolf } & 20 & 0.21 & 5.52 & 6.86 & 6.86 & 9.56 & 6.86 \\
& 40 & -0.61 & 7.77 & 9.99 & 9.99 & 14.22 & 9.99 \\
& 60 & -2.53 & 6.73 & 9.37 & 9.37 & 13.98 & 9.37 \\
& 80 & -5.91 & 2.43 & 4.83 & 4.83 & 8.84 & 4.83 \\
\hline \multirow{4}{*}{ Linx } & 20 & 1.56 & 8.17 & 19.69 & 6.44 & 8.99 & 12.23 \\
& 40 & 2.00 & 12.17 & 29.89 & 9.65 & 13.61 & 18.61 \\
& 60 & 1.35 & 12.00 & 30.60 & 9.53 & 13.83 & 19.14 \\
& 80 & -0.71 & 7.66 & 22.30 & 6.13 & 9.68 & 13.86 \\
\hline \multirow{6}{*}{ Salamander } & 20 & -2.43 & 1.42 & 7.82 & 1.29 & 3.08 & 5.14 \\
& 40 & -4.07 & 1.94 & 11.81 & 1.96 & 4.81 & 8.11 \\
& 60 & -5.03 & 1.55 & 12.12 & 1.99 & 5.19 & 8.97 \\
& 80 & -5.49 & 0.25 & 8.85 & 1.22 & 4.21 & 7.85 \\
\hline
\end{tabular}

Table 8: WTP and confidence intervals for wolves, lynx and salamanders (in $€$ )

Figure 2: Krinsky-Robb confidence intervals for WTP for conserving wolves, in class one and two (in €)
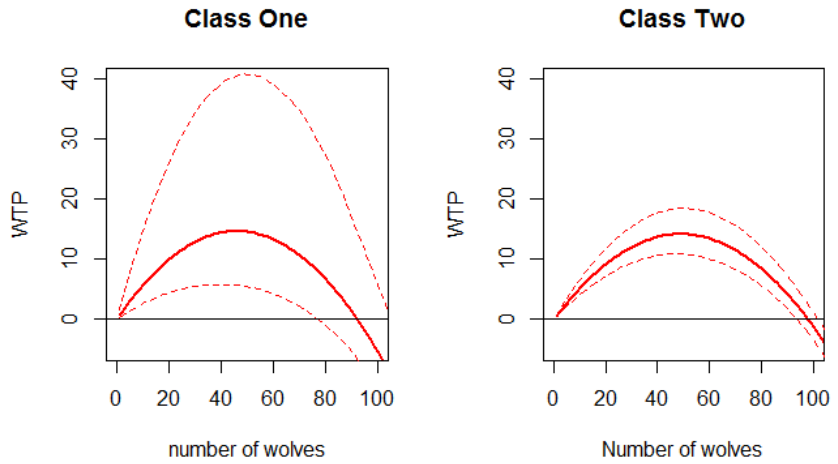

Figure 3: Krinsky-Robb confidence intervals for WTP for conserving lynx, in class one and two (in €)
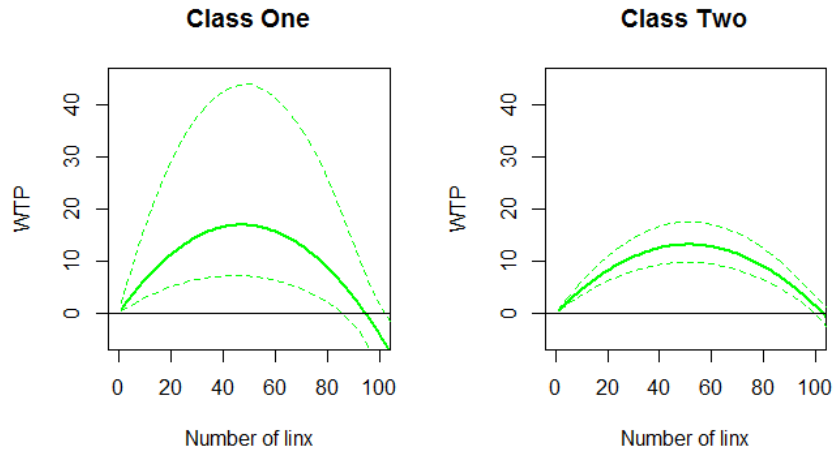

and upper borders of the confidence interval, estimated at a confidence level of 95 percent. Individual WTPs in each class follow a similar concave trend, given by the marginal utility, which is increasing until a certain size of the population and then decreasing. People are willing to contribute with higher amounts to increase the number of animals until a certain threshold. This might be explained by the fact that people are aware of the importance of biological conservation but, at the same time, they do not want too many specimen for public safety or public security reasons. Beyond the threshold, people show a still positive WTP but with a 
Figure 4: Krinsky-Robb confidence intervals for WTP for conserving salamanders, in class one and two (in €)
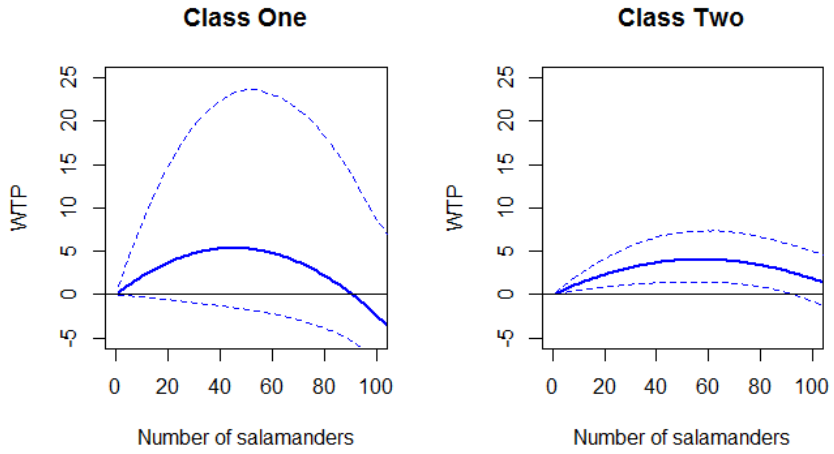

decreasing trend, until reaching zero WTP at a certain population level, which differ by animal.

From table 8, it can be noticed that, on average, the highest levels of WTP for wolves is found for a population size between 40 and 60 individuals, although confidence intervals are quite large and exact estimates are difficult to establish. Including VOs resulted in consistent differences between classes, in particular for what concern the range of confidence interval, which is always much larger in the first class. In class number one people are willing to pay roughly between $€ 6.70$ and $€ 7.70$ for such population sizes, while in class number two WTP rises to around $€ 14$, with a much smaller interval range compared to class number one. In class one, the lower confidence interval for WTP is very close to zero and turn negative at about 30 wolves, while in class number two WTP becomes negative only in correspondence of about 90 individuals. The maximum WTP for lynx and salamanders may be found for similar population sizes, but with different amount of money. There are not big differences between classes in terms of average WTP for the lynx, in fact people are willing to pay a maximum of $€ 12-13.50$ in both classes. Eventually, salamanders showed the lowest level of preference from respondents. This result was expected, because the scientific literature on biodiversity evaluation indicates people are generally willing to pay more for mammals than for reptiles and other species (Martin-Lopez et al., 2008). This result is consistent with the similarity principle, stating that man prefers the species most similar to himself (Tisdell et al., 2005; Metrick and Weitzman, 1996). The maximum WTP is between 40 and 60 salamanders, in the first class people are willing to pay a maximum of about $€ 1.50-2$ for a viable population, while in class number two WTP rises up to about $€ 5$ for the same population size.

In general, it can be observed that respondents that are more likely to be in class number two have higher WTPs for the three animals. These people are also more likely to have a mutualism orientation, their behaviour is therefore explained by a higher positive attitudes towards animals' right of existence. Conversely, WTPs in class number one are, on average, considerably smaller but with a higher variability. Class one is mainly composed by respondents with a domination orientation, whose willingness to conserve wildlife is typically smaller than for people with a mutualism orientation. For this reason, the smaller average WTP is understandable. The high variability of the confidence interval might be explained by the fact that, according to answer to value orientation questions (table 4), few people showed a domination orientation, which may have increased the variance of answers to choice tasks. At the same time, the relative small interest towards wildlife might have caused a small engagement in taking the survey, thus leading to a higher variability of answers (Hess and Stathopoulos, 2013).

Results from this study suggest that VOs are important to explain heterogeneity in preferences, bringing to a more accurate estimation of WTP for wildlife conservation. The use of a latent variable model was justified by the need of avoiding endogeneity, which is demostrated to have relevant consequencies in CE studies (Budziski and Czajkowski, 2017; Hoyos et al., 2017). Considering VOs in wildlife management has interesting policy implications. Understanding how orientations of tourists affect preferences about wildlife facilitates an ex-ante evaluation of the effects of new management strategies. Such information is important to communicate management decisions effectively and reduce the probability of conflicts. The human-wildlife conflict is the most substantial limitation to wildlife conservation policies (Dickman, 2010; Kubo and Shoji, 2014) 
and can influence a number of economic and recreational activities related to wildlife (Burns, 2004a). Understanding the individual factors and context for human-wildlife relationships is useful for the development of conservation management actions that depend on public support (Dietsch et al., 2016). The segmentation approach presented in this paper can be a useful tool for understanding target audiences and to improve WTP estimates. Results can provide guidance on the social acceptability of management interventions and can help the identification of suitable tools aimed at increasing social consensus. They can support public decision-makers in the modulation of wildlife management policies for balancing the needs of conservation and outdoor recreation, explicitly considering existing human-wildlife conflicts.

Our study was limited to the evaluation of preferences among tourists, however another critical issue in the human-wildlife interactions is represented by opinions of the locals. Local communities play an important role in conservation and, at the same time, are also a group that could be affected by decisions on natural resource management (Paletto et al., 2014; Parkins and Mitchell, 2005). VOs and preferences of the local may be different, therefore understanding opinions of a wider audience would lead to better decisions.

\section{Conclusions}

This paper discussed a methodology to include tourists' VO towards wildlife in a choice model. A system of equations, in which indicator equations and choice models are linked by means of two latent variables, was created in order to include VOs questions in the model, thus overcoming problems of endogeneity. Latent variables, representing mutualism and domination orientations, entered the indicator model as explanatory variables and the choice model as a variable affecting class membership of the respondents. The procedure was tested in a case study in the Italian Alps, the province of Trento, where a natural return of wolves and lynx from neighbouring areas was experienced in the recent years. Moreover, the area is inhabited by a unique sub-species of salamander, called salamander of Aurora. It important to consider some aspects of this study when interpreting the results. In particular, a real management of wildlife might have problems related to correlated population sizes for the animals we considered. In addition, the use of a hypothetical null alternative as opt out could be avoided in future studies if a SQ bias is expected not to influence results. We also recognize that wildlife management should be done with the investigation of preferences of all stakeholder groups, therefore local communities should also be surveyed for an effective policy-making.

Results showed that latent variables describing domination and mutualism orientations have a significant effect on latent class allocation. Differences among classes were found in the marginal utilities associated with each attribute. In terms of WTPs, the two classes were proved to be different concerning the maximum level of WTP, in the range of confidence intervals and in the maximum acceptable number of specimen. In class one, people showed the highest average WTP for lynx and then for wolves. WTP for wolves was assessed to be around $€ 12-13.50$ for a population of about 40-60 animals, while WTP for wolves was about $€ 6.70-7.70$ for the same range of population size. In class two, people showed higher WTP for the wolves rather than lynx, ie. $€ 14$, while the average maximum WTP for lynx is almost the same as in class one. In both classes, WTP for salamander is considerably lower than for the two mammal species. Confirming previous literature, our results demonstrated the positive attitude of the majority of tourists towards wildlife, indicated by the size of the class where mutualists are more likely to belong and by the amount they are willingness to pay for increasing specimens. This finding is significant because it confirms that VOs are relevant when one wishes to explain heterogeneity in WTP and should be included to improve welfare analysis. In addition, our study further provides evidence of a societal shift from domination to mutualism.

The characterization of tourists that the model proposed is useful not only to circumvent statistical problems such as endogeneity, but also for decision-makers, to tailor effective conservation policies. Humanwildlife conflict is the most substantial limitation to wildlife conservation policies (Dickman, 2010; Kubo and Yasushi, 2014) and can influence a number of economic and recreational activities related to wildlife (Burns, 2004b). The described hybrid model is able to provide a description of preferences based on individual characteristics, so that preference heterogeneity can be effectively modelled. 
What emerged from the study is that lynx and wolf are seen by tourists as symbols of the Alps and their presence probably is one of the major reasons that make Trentino one of the strongest national attractions in a naturalistic environment. This phenomenon may have some policy implications on economic and recreational activities related to wildlife, such as wildlife tourism. One of the key points for a successful wildlife tourism experience is the attitude of tourists towards wildlife (Reynolds and Braithwaite, 2001). Our psychological and economic results show that wildlife tourism can be developed in Trentino. Wildlife tourism could bring further benefits in terms of environmental education and awareness both for tourists and local population, helping in reducing the human wildlife conflict, which in recent years has increased in Trentino. As the case of the salamander aurora shows, a lack of knowledge and familiarity with a particular wild species can affect the preferences of tourists and therefore availability to support any protection and conservation plans. Tourist experience based on observation, familiarization with the characteristics and habits of these wild animals, can produce positive effects both for sustainable tourism development and wildlife conservation.

\section{Acknowledgements}

We are thankful to professor J.J. Vaske for sharing the questionnaire on value orientation and to Valentina Manini, Serena Nichele and Alessio Tamanini for the help with data compilation.

\section{References}

Abou-Zeid, M., Ben-Akiva, M., Bierlaire, M., Choudhury, C., and Hess, S. (2010). Attitudes and value of time heterogeneity. Applied Transport Economics-A Management and Policy Perspective. De Boeck Publishing, pages $523-545$.

Agimass, F., Vedel, S. E., and Jacobsen, J. B. (2017). Accounting for environmental attitude to explain variations in willingness to pay for forest ecosystem service using the new environmental paradigm. EAERE, European Association for Environmental and Resource Economics, Athens (Greece), pages 1-28.

Agnolin, M. (2012). Analisi delle preferenze dei residenti per la gestione dell'orso (ursus arctos) in trentino. Master thesis, University of Trento.

Arrow, K., Solow, R., Portney, P. R., Leamer, E. E., Radner, R., and Schuman, H. (1993). Report of the noaa panel on contingent valuation. Federal register, 58(10):4601-4614.

Bell, J., Huber, J., and Viscusi, W. K. (2011). Survey mode effects on valuation of environmental goods. International journal of environmental research and public health, 8(4):1222-1243.

Ben-Akiva, M., McFadden, D., Gärling, T., Gopinath, D., Walker, J., Bolduc, D., Börsch-Supan, A., Delquié, P., Larichev, O., Morikawa, T., et al. (1999). Extended framework for modeling choice behavior. Marketing letters, 10(3):187-203.

Ben-Akiva, M., McFadden, D., Train, K., Walker, J., Bhat, C., Bierlaire, M., Bolduc, D., Boersch-Supan, A., Brownstone, D., Bunch, D. S., et al. (2002). Hybrid choice models: progress and challenges. Marketing Letters, 13(3):163-175.

Birol, E., Karousakis, K., and Koundouri, P. (2006). Using a choice experiment to account for preference heterogeneity in wetland attributes: the case of cheimaditida wetland in greece. Ecological economics, $60(1): 145-156$.

Bjerke, T., Ødegårdstuen, T. S., and Kaltenborn, B. P. (1998). Attitudes toward animals among norwegian children and adolescents: species preferences. Anthrozoös, 11(4):227-235.

Bliemer, M. C., Rose, J. M., and Hess, S. (2008). Approximation of bayesian efficiency in experimental choice designs. Journal of Choice Modelling, 1(1):98-126. 
Bolduc, D. and Alvarez-Daziano, R. (2010). On estimation of hybrid choice models. In Choice Modelling: The State-of-the-Art and the State-of-Practice: Proceedings from the Inaugural International Choice Modelling Conference. Emerald Group Publishing, page 259.

Bolduc, D., Ben-Akiva, M., Walker, J., and Michaud, A. (2005). Hybrid choice models with logit kernel: applicability to large scale models. Integrated Land-Use and Transportation Models: Behavioural Foundations, Elsevier, Oxford, pages 275-302.

Boxall, P. C., Adamowicz, W. L., Swait, J., Williams, M., and Louviere, J. (1996). A comparison of stated preference methods for environmental valuation. Ecological economics, 18(3):243-253.

Brown, T. C. (1984). The concept of value in resource allocation. Land economics, 60(3):231-246.

Budziski, W. and Czajkowski, M. (2017). Addressing endogeneity in hybrid choice models. EAERE, European Association for Environmental and Resource Economics, Athens (Greece), pages 1-21.

Burns, G. L. (2004a). The host community and wildlife tourism. Wildlife tourism, 125.

Burns, G. L. (2004b). The host community and wildlife tourism. In Higginbottom, K., editor, Wildlife Tourism, Impacts, Management and Planning, pages 125-144. Common Ground Publishing Pty.

Campbell, D., Boeri, M., Doherty, E., and Hutchinson, W. G. (2015). Learning, fatigue and preference formation in discrete choice experiments. Journal of Economic Behavior and Organization, pages 1-19.

Campbell, D., Hensher, D. A., and Scarpa, R. (2012). Cost thresholds, cut-offs and sensitivities in stated choice analysis: identification and implications. Resource and Energy Economics, 34(3):396-411.

Carlsson, F. and Johansson-Stenman, O. (2000). Willingness to pay for improved air quality in sweden. Applied Economics, 32(6):661-669.

Choi, A. S. and Fielding, K. S. (2013). Environmental attitudes as wtp predictors: A case study involving endangered species. Ecological Economics, 89:24-32.

Daly, A., Hess, S., Patruni, B., Potoglou, D., and Rohr, C. (2012). Using ordered attitudinal indicators in a latent variable choice model: a study of the impact of security on rail travel behaviour. Transportation, 39(2):267-297.

Delibes-Mateos, M., Giergiczny, M., Caro, J., Viñuela, J., Riera, P., and Arroyo, B. (2014). Does hunters' willingness to pay match the best hunting options for biodiversity conservation? a choice experiment application for small game hunting in spain. Biological Conservation, 177:36-42.

Di Minin, E., Fraser, I., Slotow, R., and MacMillan, D. C. (2013). Understanding heterogeneous preference of tourists for big game species: implications for conservation and management. Animal Conservation, $16(3): 249-258$.

Dickman, A. J. (2010). Complexities of conflict: the importance of considering social factors for effectively resolving human-wildlife conflict. Animal conservation, 13(5):458-466.

Dietsch, A. M., Teel, T. L., and Manfredo, M. J. (2016). Social values and biodiversity conservation in a dynamic world. Conservation Biology, 30(6):1212-1221.

Flynn, T. N., Louviere, J. J., Peters, T. J., and Coast, J. (2007). Best-worst scaling: what it can do for health care research and how to do it. Journal of health economics, 26(1):171-189.

Fulton, D. C., Manfredo, M. J., and Lipscomb, J. (1996). Wildlife value orientations: A conceptual and measurement approach. Human dimensions of wildlife, 1(2):24-47.

Gamborg, C. and Jensen, F. S. (2017). Attitudes towards recreational hunting: A quantitative survey of the general public in denmark. Journal of Outdoor Recreation and Tourism, 17:20-28. 
Greene, W. H. (2003). Econometric analysis. Pearson Education India.

Greene, W. H. and Hensher, D. A. (2003). A latent class model for discrete choice analysis: contrasts with mixed logit. Transportation Research Part B: Methodological, 37(8):681-698.

Han, S.-y., Lee, C.-k., Mjelde, J. W., and Kim, T.-k. (2010). Choice-experiment valuation of management alternatives for reintroduction of the endangered mountain goral in Woraksan National Park, South Korea. Scandinavian Journal of Forest Research, 25:534-543.

Hanemann, W. M. (1984). Welfare evaluations in contingent valuation experiments with discrete responses. American journal of agricultural economics, 66(3):332-341.

Hanley, N., Czajkowski, M., Hanley-Nickolls, R., and Redpath, S. (2010). Economic values of species management options in human-wildlife conflicts: Hen harriers in scotland. Ecological Economics, 70(1):107-113.

Hanley, N., MacMillan, D., Patterson, I., and Wright, R. E. (2003). Economics and the design of nature conservation policy: a case study of wild goose conservation in scotland using choice experiments. Animal conservation, 6(02):123-129.

Hanley, N., MacMillan, D., Wright, R. E., Bullock, C., Simpson, I., Parsisson, D., and Crabtree, B. (1998). Contingent valuation versus choice experiments: estimating the benefits of environmentally sensitive areas in scotland. Journal of agricultural economics, 49(1):1-15.

Hartel, C. M., Carlton, J. S., and Prokopy, L. S. (2015). The role of value orientations and experience on attitudes toward a well-liked threatened reptile. Human Dimensions of Wildlife, 20(6):553-562.

Hermann, N., Voß, C., and Menzel, S. (2013). Wildlife value orientations as predicting factors in support of reintroducing bison and of wolves migrating to germany. Journal for Nature Conservation, 21(3):125-132.

Hess, S. and Beharry-Borg, N. (2012). Accounting for latent attitudes in willingness-to-pay studies: the case of coastal water quality improvements in tobago. Environmental and Resource Economics, 52(1):109-131.

Hess, S., Shires, J., and Jopson, A. (2013). Accommodating underlying pro-environmental attitudes in a rail travel context: application of a latent variable latent class specification. Transportation Research Part D: Transport and Environment, 25:42-48.

Hess, S. and Stathopoulos, A. (2013). Linking response quality to survey engagement: a combined random scale and latent variable approach. Journal of choice modelling, 7:1-12.

Hole, A. R. (2007). A comparison of approaches to estimating confidence intervals for willingness to pay measures. Health economics, 16(8):827-840.

Homer, P. M. and Kahle, L. R. (1988). A structural equation test of the value-attitude-behavior hierarchy. Journal of Personality and social Psychology, 54(4):638.

Howell, S. E. and Laska, S. B. (1992). The changing face of the environmental coalition: a research note. Environment and Behavior, 24(1):134-144.

Hoyos, D. (2010). The state of the art of environmental valuation with discrete choice experiments. Ecological economics, 69(8):1595-1603.

Hoyos, D., Mariel, P., Artabe, A., and Guevara, A. (2017). Dealing with endogeneity in discrete-choice models for environmental valuation: preliminary results. EAERE, European Association for Environmental and Resource Economics, Athens (Greece), pages 1-25.

Hoyos, D., Mariel, P., and Hess, S. (2015). Incorporating environmental attitudes in discrete choice models: An exploration of the utility of the awareness of consequences scale. Science of the Total Environment, 505:1100-1111. 
Hrubes, D., Ajzen, I., and Daigle, J. (2001). Predicting hunting intentions and behavior: An application of the theory of planned behavior. Leisure Sciences, 23(3):165-178.

Jacobs, M. H., Vaske, J. J., and Sijtsma, M. T. (2014). Predictive potential of wildlife value orientations for acceptability of management interventions. Journal for Nature Conservation, 22(4):377-383.

Johnston, R. J., Boyle, K. J., Adamowicz, W., Bennett, J., Brouwer, R., Cameron, T. A., Hanemann, W. M., Hanley, N., Ryan, M., Scarpa, R., et al. (2017). Contemporary guidance for stated preference studies. Journal of the Association of Environmental and Resource Economists, 4(2):319-405.

Kansky, R., Kidd, M., and Knight, A. T. (2016). A wildlife tolerance model and case study for understanding human wildlife conflicts. Biological Conservation, 201:137-145.

Kellert, S. R. (1980). Contemporary values of wildlife in american society. Wildlife Values. Center for Assessment of Noncommodity Natural Resource Values, Institutional Series Report, 1:241-267.

Kubo, T. and Shoji, Y. (2014). Trade-off between human-wildlife conflict risk and recreation conditions. European journal of wildlife research, 60(3):501-510.

Kubo, T. and Yasushi, S. (2014). Spatial tradeoffs between residents preferences for brown bear conservation and the mitigation of humanbear conflicts. Biologicall Conservation, 176:126-132.

Lindhjem, H. and Navrud, S. (2011). Are internet surveys an alternative to face-to-face interviews in contingent valuation? Ecological economics, 70(9):1628-1637.

Manfredo, M. J. (2008). Who cares about wildlife? Springer.

Manfredo, M. J., Teel, T. L., and Dietsch, A. M. (2016). Implications of human value shift and persistence for biodiversity conservation. Conservation Biology.

Manfredo, M. J., Teel, T. L., and Henry, K. L. (2009). Linking society and environment: A multilevel model of shifting wildlife value orientations in the western united states. Social Science Quarterly, 90(2):407-427.

Manski, C. F. (1977). The structure of random utility models. Theory and Decision, 8:229-254.

Martin-Lopez, B., Montes, C., and Benayas, J. (2008). Economic valuation of biodiversity conservation: the meaning of numbers. Conservation Biology, 22(3):624-635.

Metrick, A. and Weitzman, M. L. (1996). Patterns of behavior in endangered species preservation. Land Economics, pages 1-16.

Milon, J. W. and Scrogin, D. (2006). Latent preferences and valuation of wetland ecosystem restoration. Ecological Economics, 56(2):162-175.

Morey, E., Thiene, M., De Salvo, M., and Signorello, G. (2008). Using attitudinal data to identify latent classes that vary in their preference for landscape preservation. Ecological Economics, 68(1):536-546.

Ojea, E. and Loureiro, M. L. (2007). Altruistic, egoistic and biospheric values in willingness to pay (wtp) for wildlife. Ecological Economics, 63(4):807-814.

Olsen, S. B., Campbell, D., and Mørkbak, M. R. (2012). Assessing the impact of opt-out definitions in choice experiments: a case study on food safety. In European Association of Environmental and Resource Economists.

Paletto, A., Giacovelli, G., Grilli, G., Balest, J., and De Meo, I. (2014). Stakeholders preferences and the assessment of forest ecosystem services: a comparative analysis in italy. Journal of Forest Science, 60(11):472-483.

Parkins, J. R. and Mitchell, R. E. (2005). Public participation as public debate: a deliberative turn in natural resource management. Society and natural resources, 18(6):529-540. 
Pearce, D. (2001). Valuing biological diversity: issues and overview. OECD: Valuation of Biodiversity Benefits; Selected Studies. Paris, OECD.

R Core Team (2013). R: A Language and Environment for Statistical Computing. R Foundation for Statistical Computing, Vienna, Austria.

Ray, J. J. (1990). Acquiescence and problems with forced-choice scales. The Journal of Social Psychology, 130(3):397-399.

Reynolds, P. C. and Braithwaite, D. (2001). Toward a conceptual framework for wildlife tourism. Tourism Management, 22(1):31-42.

Riepe, C. and Arlinghaus, R. (2014). Explaining anti-angling sentiments in the general population of germany: an application of the cognitive hierarchy model. Human Dimensions of Wildlife, 19(4):371-390.

Riera, P., Signorello, G., Thiene, M., Mahieu, P.-A., Navrud, S., Kaval, P., Rulleau, B., Mavsar, R., Madureira, L., Meyerhoff, J., et al. (2012). Non-market valuation of forest goods and services: Good practice guidelines. Journal of Forest Economics, 18(4):259-270.

Rolston, H. (1994). Value in nature and the nature of value. Royal Institute of Philosophy Supplements, $36: 13-30$.

Rolston III, H. (1983). Values gone wild. Inquiry, 26(2):181-207.

Scarpa, R., Notaro, S., Louviere, J., and Raffaelli, R. (2011). Exploring scale effects of best/worst rank ordered choice data to estimate benefits of tourism in alpine grazing commons. American Journal of Agricultural Economics, 93(3):813-828.

Scarpa, R. and Thiene, M. (2005). Destination choice models for rock climbing in the northeastern alps: a latent-class approach based on intensity of preferences. Land economics, 81(3):426-444.

Serenari, C., Peterson, M. N., Gale, T., and Fahlke, A. (2015). Relationships between value orientations and wildlife conservation policy preferences in chilean patagonia. Human Dimensions of Wildlife, 20(3):271279 .

Shen, J. (2009). Latent class model or mixed logit model? a comparison by transport mode choice data. Applied Economics, 41(22):2915-2924.

Spash, C. L. (2006). Non-economic motivation for contingent values: rights and attitudinal beliefs in the willingness to pay for environmental improvements. Land Economics, 82(4):602-622.

Sponarski, C. C., Vaske, J. J., Bath, A., and Musiani, M. M. (2014). Salient values, social trust, and attitudes toward wolf management in south-western alberta, canada. Environmental Conservation, 41(4):303-310.

Sponarski, C. C., Vaske, J. J., and Bath, A. J. (2015). The role of cognitions and emotions in human-coyote interactions. Human Dimensions of Wildlife, 20(3):238-254.

Steinhoff, H. W. (1980). Analysis of major conceptual systems for understanding and measuring wildlife values. Wildlife Values Proceedings.

Tattoni, C., Grilli, G., and Ciolli, M. (2017). Advertising value of the brown bear in the italian alps. Ursus, $27(2): 110-121$.

Teel, T. L. and Manfredo, M. J. (2010). Understanding the diversity of public interests in wildlife conservation. Conservation Biology, 24(1):128-139.

Teel, T. L., Manfredo, M. J., Jensen, F. S., Buijs, A. E., Fischer, A., Riepe, C., Arlinghaus, R., and Jacobs, M. H. (2010). Understanding the cognitive basis for human-wildlife relationships as a key to successful protected-area management. International Journal of Sociology, 40(3):104-123. 
Tisdell, C., Wilson, C., and Nantha, H. S. (2005). Association of public support for survival of wildlife species with their likeability. Anthrozoös, 18(2):160-174.

Vaske, J. J., Jacobs, M. H., and Sijtsma, M. T. (2011). Wildlife value orientations and demographics in the netherlands. European Journal of Wildlife Research, 57(6):1179-1187.

Wallmo, K. and Lew, D. K. (2011). Valuing improvements to threatened and endangered marine species: an application of stated preference choice experiments. Journal of environmental management, 92(7):17931801.

Whittaker, D., Vaske, J. J., and Manfredo, M. J. (2006). Specificity and the cognitive hierarchy: Value orientations and the acceptability of urban wildlife management actions. Society and Natural Resources, $19(6): 515-530$.

Whittington, D., Adamowicz, W., and Lloyd-Smith, P. (2017). Asking willingness-to-accept questions in stated preference surveys: A review and research agenda. Annual Review of Resource Economics, (0).

Winslott Hiselius, L. (2005). Using choice experiments to assess people's preferences for railway transports of hazardous materials. Risk Analysis, 25(5):1199-1214.

Wiser, R. H. (2007). Using contingent valuation to explore willingness to pay for renewable energy: a comparison of collective and voluntary payment vehicles. Ecological economics, 62(3-4):419-432. 